Vol. 7 No. 1, April 2021 (40-47)

JURNAL KEOLAHRAGAAN

https://jurnal.unigal.ac.id/index.php/JKP

\title{
Peranan Motor Educability Dalam Low Rope Circuit Activity Pada Kegiatan Outbound
}

\author{
Hendra Rustiawan ${ }^{1}$, Andang Rohendi ${ }^{2}$ \\ ${ }^{12}$ Program Studi Pendidikan Jasmani, Universitas Galuh, Ciamis, Indonesia \\ Email: hendra6610111972@gmail.com
}

\begin{abstract}
The teaching and learning process in the PJKR study program was not only in the classroom but also outside the classroom. Because there were several subjects that required practice in the field other than in the classroom, such as soccer, volleyball, basketball and PLS (Outside School Education). Because as a physical education teacher candidate it was not only limited to physical education subjects but more than that, because in the school environment usually those who were trusted in school activities, especially outdoor activities appointed by the principal or deputy principal of the school were usually physical education teachers, so the Galuh University PJKR study program tries preparing human resources (human resources), namely prospective physical education teachers to always be ready to carry out the duties of the school, one of which is being able to have knowledge in terms of outdoor activities such as outbound activities. This outbound activity consists of catchen crawl, two line bridges, elvis travers, commando crawl, tarzan travers, and hebee zebee and the results obtained and felt by the outbound participants were very pronounced starting from the physical conditions that must be prepared such as strength, speed, power, muscle endurance, cardiovascular endurance, flexibility, balance, coordination, agility, accuracy, and reaction, as well as outbound knowledge so that students have scientific insight and experience about motor educability and outbound activities that can later be used when they become physical education teachers or instructors. outbound.
\end{abstract}

Keywords: Low rope circuit, Motor educability, Outbound, Physical condition,

\begin{abstract}
ABSTRAK
Proses belajar mengajar dilingkungan prodi PJKR tidak hanya di ruang kelas namun di luar kelas pun ada. Karena ada beberapa mata kuliah yang membutuhkan praktek di lapangan selain di kelas, seperti sepak bola, bola voli, bola basket dan PLS (Pendidikan Luar Sekolah). Karena sebagai calon guru penjas tidak hanya terbatas pada mata pelajaran pendidikan jasmani namun lebih dari itu, karena di lingkungan sekolah biasanya yang dipercaya dalam kegiatan sekolah terutama kegiatan outdoor yang ditunjuk oleh kepala sekolah atau wakil kepala sekolah biasanya guru penjas, sehingga prodi PJKR Universitas Galuh berusaha mempersiapkan SDM (sumber daya manusia) yaitu calon guru penjas untuk senantiasa siap mengemban tugas dari sekolah salah satunya mampu memiliki pengetahuan dalam hal kegiatan outdoor seperti outbound. Kegiatan outbound ini terdiri dari catchen crawl, two line bridge, elvis travers, commando crawl, tarzan travers, dan hebee zebee dan hasil yang didapat dan dirasakan oleh para peserta outbound ini sangat terasa mulai dari kondisi fisik yang harus dipersiapkan seperti kekuatan, kecepatan, power, daya tahan otot, daya tahan kardiovaskular, fleksibilitas, keseimbangan, koordinasi, kelincahan, akurasi, dan reaksi, serta pengetahuan tentang outbound sehingga para mahasiswa memiliki wawasan keilmuan dan pengalaman tentang motor educability dan outbound yang kelak dapat digunakan ketika mereka menjadi guru penjas atau instruktur outbound.
\end{abstract}

Kata Kunci: Kondisi fisik, Low rope circuit, Motor educability, Outbound Kegiatan Outbound. Jurnal Keolahragaan Pendidikan Jasmani. Unigal, 7(1), 40-47. 


\section{PENDAHULUAN}

Program studi PJKR yang sekarang berganti nama menjadi program studi Pendidikan Jasmani tidak hanya menyelenggarakan mata kuliah pada lingkungan pendidikan jasmani dan olahraga prestasi, akan tetapi menyelenggarakan olahraga yang bersifat petualangan dan mengandung unsur permainan atau games dengan tujuan untuk memberikan pembekalan agar memiliki tingkat kemampuan yang diperoleh mahasiswa agar siap ketika ditempatkan atau bekerja pada lapangan pekerjaan seperti di sekolah atau lapangan pekerjaan mengandung unsur pendidikan yang menuntut berbagai variasi pembelajaran serta dapat mencintai, melestarikan, dan memanfaatkan hutan sebagai media proses pembelajaran yang selama ini hanya terbatas di lingkungan sekolah atau di kelas.

Calon-calon guru pendidikan jasmani yang ada di Pendidikan Jasmani Universitas Galuh pada umumnya bekerja di lingkungan pendidikan pada tingkatan sekolah dasar, menengah, dan atas yang merupakan objek sasarannya adalah anak-anak dan remaja yang cenderung secara psikologis usia tersebut adalah usia bermain. Lutan (2001:17) mengatakan. "Sesuai dengan kodratnya, anak senang bermain. Ia senang melampiaskan kebebasannya untuk bergerak. Melalui bermain, anak disiapkan untuk menghadapi kehidupan nyata. Bermain mengajarkan kenyataan hidup".

Tidak hanya itu saja, olahraga yang bersifat permainan atau games yang terdapat pada pendekatan taktis akan memberikan rasa senang, serta menuntut bagaimana menyelesaikan masalah dalam permainan tersebut. Subroto (2010:5) menjelaskan, "Bagi siswa, tujuan pembelajaran dengan menggunakan pendekatan taktis adalah :

1) Meningkatkan kemampuan bermain melalui pemahaman terhadap keterkaitan antara taktik permainan dan perkembangan keterampilan.

2) Memberikan kesenangan dalam proses pembelajaran.

3) Belajar memecahkan masalah-masalah dan membuat keputusan selama bermain.

Berdasarkan penjelasan dari ke dua pakar di atas, penulis menyimpulkan bahwa pendidikan jasmani dan olahraga permainan di alam dapat memberikan motivasi untuk memecahkan masalah yang dihadapi dengan rasa senang dan penuh tantangan dan ketika berhasil menyelesaikan masalah siswa dapat merasakan kepuasaan.

Dengan melaksanakan olahraga permainan di alam dapat memberikan dan menumbuhkan motivasi yang tinggi pada ranah motivasi keberhasilan, motivasi dalam diri, motivasi berbagai tingkatan dan kemampuan siswa. Suherman (2009:121-123) menjelaskan bahwa, "Ada tiga kunci dalam memotivasi siswa berlatih :

1) Berorientasi pada keberhasilan. Dapat menguasai tugas gerak yang diberikan.

2) Memotivasi secara Intrinsik. Guru harus memotivasi siswa bekerja keras sehingga memperoleh kepuasaan dari hasil yang diperolehnya.

3) Sesuai dengan Tingkat Perkembangan. Guru harus mampu menciptakan aktivitas belajar yang dapat mencerminkan berbagai perbedaan kemampuan dan usia siswa.

Jenis petualangan dalam penelitian ini termasuk pada pendidikan petualangan (Adventure Education) yang memanfaatkan alam bebas tanpa harus merusak alam itu sendiri. Dalam pendidikan petualangan ini tidak hanya memanfaatkan alam namun menambahkan beberapa alat bantu seperti tali baja, tali tambang, perahu karet (banana), rompi pelampung, helm, alat dayung, dan perlengkapan lainnya untuk mendukung kegiatan outbound ini. Rahyubi (2012:354) mengutarakan "Pendidikan petualangan dikembangkan atas dasar kebutuhan untuk mengatasi tekanan-tekanan hidup yang semakin berat. Programnya berisi aktivitas yang menantang di alam bebas dan disesuaikan dengan kebutuhan para peserta didik untuk berpetualang mengatasi resiko dan perjuangan melawan tantangan alam. Mendaki gunung, menyusuri sungai, berkemah, memanjat tebing, dan variasi lain di alam terbuka merupakan contoh program pendidikan petualangan". 
Berdasarkan penjelasan di atas yang diterapkan dalam penelitian ini tidak seluruhnya memanfaatkan alam namun adanya penambahan perlengkapan dengan lokasi alam yang tidak jauh antara games yang satu dengan games yang lain sehingga peserta tidak terlalu lelah dari pos games yang satu ke pos games yang lain dan cenderung semua peserta ingin merasakan dan mencoba seluruh games yang disediakan oleh panitia.

Karena aktivitas ini tidak terlepas dari pendidikan jasmani dan pelaksanaannya di alam bebas, namun tetap tidak akan terlepas dari tujuan pendidikan jasmani yaitu empat domain yaitu kognitif, afektif, psikomotorik, dan fisik. Hal ini diperkuat oleh Rahyubi (2012:356) menjelaskan, "Tujuan pendidikan dan pembelajaran dibagi dalam empat domain, yaitu kognitif, afektif, psikomotor, dan fisik". Dari keempat domain tersebut penulis akan menjelaskan satu persatu sebagai berikut.

1. Pada aspek Kognitif peserta memiliki wawasan baru dengan pengembangan pendidikan jasmani dan olahraga yang pelaksanaannya di alam sehingga peserta memahami pemanfaatan alam untuk pengembangan tingkat kebugaran jasmani.

2. Pada aspek Afektif mengembangkan perasaan dan perilaku peserta agar mampu memiliki kemampuan manajemen kelompok, kerjasama, tenggang rasa antara anggota peserta, memberikan kepercayaan diri baik pada masing-masing peserta, serta pembentukan mental dengan nuansa lokasi baru.

3. Pada aspek Psikomotorik mencoba tugas gerak dan keterampilan gerak yang baru dengan mencoba kemampuan fungsional tubuh pada komponen kondisi fisik kekuatan, kecepatan, power (daya ledak), dan daya tahan otot.

4. Pada aspek fisik bertujuan untuk mengembangkan potensi kemampuan fisik yang ada pada setiap masing-masing peserta dalam melakukan games sampai dapat menyelesaikan dengan baik. Dalam aspek ini mencoba menguji kemampuan dan keterampilan baik secara individu maupun secara kelompok.

\section{Kegiatan Outbound di Pendidikan Jasmani}

Pendidikan Rekreasi adalah salah satu mata kuliah yang ada pada program studi Pendidikan Jasmani Universitas Galuh Ciamis yang di dalamnya mencakup pembahasan materi tentang pendidikan jasmani dan olahraga dalam lingkup olahraga kesehatan yang diarahkan pada rekreasi dan cenderung pelaksanaan olahraga prakteknya adalah outdoor yang biasa disebut dengan istilah outbound. Hal ini memanfaatkan alam yang ada tanpa harus merubah atau merusak kondisi alam yang sebenarnya, seperti, tanah (lapangan tumput, air (sungai, danau), dan pohon, yang sudah biasa dilaksanakan oleh Prodi Pendidikan Jasmani Universitas Galuh adalah bersifat outbound, hal ini merupakan dasar pengembangan dari mata kuliah Pendidikan rekreasi.

Kegiatan semacam ini sudah biasa dilaksanakan oleh prodi Pendidikan Jasmani, namun sepertinya belum ada yang melakukan penelitian yang berhubungan dengan kegiatan outbound ini. Sedangkan manfaat kegiatan ini sangat banyak meskipun waktu pelaksanaannya hanya satu hari, hampir dari segala aspek di uji dalam kegiatan outbound ini.

Apabila dilihat dari aspek fisiologi yang diarahkan pada komponen kondisi fisik secara ilmu pendidikan kepelatihan dari Sajoto (1988:4) bahwa unsur-unsur komponen kondisi fisik yang terlibat adalah sebagai berikut :

1. Strenght (Kekuatan)

2. Speed (Kecepatan)

3. Power (Daya ledak)

4. Muscle endurance (Daya tahan oto lokal)

5. Cardio-respiratory endurance (Daya tahan jantung dan paru-paru)

6. Flexibility (Kelntukan)

7. Balance (Keseimbangan) 
8. Coordination (Koordinasi)

9. Agility (Kelincahan)

10. Accuracy (Ketepatan)

11. Reaction (Reaksi)

Berdasarkan komponen kondisi fisik tersebut dan berdasarkan pengamatan langsung dari tim dosen yang sekaligus sebagai anggota panitia pelaksanaan kegiatan tersebut, penulis berasumsi bahwa dalam kegiatan outbound yang sudah dilaksanakan pada tanggal 25 Januari 2015 oleh prodi Pendidikan Jasmani Universitas Galuh Ciamis, melibatkan sebelah komponen kondisi fisik yang tercantum di atas, dapat meningkatkan hubungan kerjasama tim diantara para mahasiswa regular dan mahasiswa kelas karyawan tingkat dua, serta mempunyai keberanian dalam melakukan tindakan beserta resikonya. Hal ini sesuai dengan penelitian dari (Khalid \& Rustiawan, 2020) yang menyebutkan bahwa komponen kondisi fisik tediri dari kekuatan, kecepatan, power, daya tahan, fleksibilitas, keseimbangan, koordinasi, kelincahan, ketepatan, dan aksi reaksi.

Kata atau kalimat pertama-tama sebelum nama outbound sudah dikenal dengan nama outward bound Indonesia pada tahun 1990. Nama outward bound ini berasal dari Dr. Kurt Hahn yang mendirikan sekolah bernuansa alam beserta pemanfaatan alam itu sendiri di Aberdovey, Wales, pada tahun 1941.

Outbound merupakan kegiatan pembelajaran karakter manusia di alam terbuka (outdoor) yang mengandung unsur petualangan dengan adanya tugas atau tekanan yang harus dipecahkan baik secara individu maupun secara tim (kelompok).

Sugandi (2013:2) mengungkapkan bahwa, "Kegiatan outbound mempunyai arti kegiatan di luar ruangan tersebut mengandung unsur permainan, edukasi, serta rekreasi. Melalui permainanpermainan ringan yang menarik, peserta dihadapkan pada suatu tantangan untuk dipecahkan secara bersama-sama dengan sejenak melepaskan atribut masingmasing. Sehingga diharapkan tercipta suasana keakraban, kebersamaan serta kerjasama tim yang nantinya bermanfaat dalam mengatasi permasalahan yang lebih besar". Pengertian di atas dapat disimpulkan bahwa tidak bisa berdiri sendiri namun harus dapat membina kerjasama tim yang harmonis sehingga dapat menghasilkan penyelesaian yang baik dalam permainan outbound secara maksimal.

Sujarwo (2011:6) menjelaskan bahwa, "Definisi outbound merupakan suatu kegiatan atau aktifitas yang dilakukan baik indoor maupun outdoor yang didalam aktivitasnya terkandung nilai-nilai yang positif guna mengembangkan kemampuan terutama softskill dalam dunia kerjanya. Sedangkan konsep dasar outbound yaitu aktifitas yang kreatif, inovatif, dan menyenangkan yang dilakukan di luar rutinitas keseharian". Sedangkan dari Susapti (2009:1) secara singkat menjelaskan, "Outbound dipahami sebagai pembelajaran yang dilakukan di luar ruang atau lebih tepatnya belajar di alam bebas".

Ancok (2002:41) adalah suatu program pelatihan di alam terbuka yang mendasarkan pada prinsip "experiental learning" (belajar melalui pengalaman langsung) yang disajikan melalui aktivitas fisik dan dikemas dalam bentuk permainan, simulasi, diskusi dan petualangan sebagai media penyampaian materi.

Berdasarkan penjelasan di atas dan dihubungkan dengan penelitian ini, penulis menyimpulkan bahwa outbound merupakan kegiatan di luar ruangan (outdoor) yang tepatnya mengarah ke alam terbuka (hutan) dengan tujuan untuk mengembangkan kemampuan diri baik secara individu yang diterapkan pada kerjasama tim atau kelompok baik pada gerak fisik (psikomotorik), maupun emosi (afektif) dan berpikir (kognitif).

Karakteristik pembelajaran di ruang kelas (indoor) sudah biasa dilaksanakan dan cenderung membosankan serta hanya menyentuh ranah kognitif saja, artinya hanya mendapatkan nilai-nilai pengetahuan dan pemahaman dalam suatu mata kuliah, sedangkan pembelajaran di alam terbuka (outdoor) dapat menyentuh lebih luas aeperti ranah kognitif, 
afektif, dan psikomotor. Balicamp (2014:2) menjelaskan bahwa, "Ruang terbuka (Outdoor) merupakan media atau prasarana yang memberikan keleluasaan baik pada gerak fisik (psikomotorik), maupun emosi (afeksi) dan berpikir (kognisi) bagi pesertanya.

Secara naluriah manusia biasanya dengan suasana baru akan menimbulkan semangat dan motivasi yang baru, memerlukan tantangan dan ingin memecahkan suatu masalah sampai berhasil, ingin memperlihatkan bahwa mampu menyelesaikan suatu tugas atau tantangan. yang dihadapi, serta merasakan kegunaan dari suatu tantangan tersebut. Masih dari Balicamp (2014:2) menjelaskan tentang sifat manusia, "Tidak menyukai suasana yang formal, karena suasana yang formal dalam belajar mengekang proses berpikir. Sedangkan bila suasananya informal dapat terjadi pertukaran ide secara luas. Orang dewasa selalu ingin memecahkan masalah, aktifitas diluar ruang selalu memiliki problema yang menantang untuk dipecahkan. Orang dewasa akan mengalami kemajuan bila menghadapi masalah-masalah yang nyata, dan dapat mempraktekkan apa yang dimilikinya untuk memecahkan masalah tersebut. Orang dewasa selalu mencari manfaat dari apa yang dialaminya".

Berdasarkan karakteristik manusia yang dijelaskan di atas maka cocok sekali diberikan pembelajaran pendidikan rekreasi dalam satu semester dilaksanakan kegiatan outdoor dengan bentuk outbound untuk mahasiswa Pendidikan Jasmani tingkat 2.

\section{Tujuan dan Manfaat Outbound}

Kegiatan outbound ini tidak semata-mata hanya untuk rekreasi dan kesenangan saja namun lebih dari itu tujuan yang paling utama adalah mengembangkan kemampuan diri, penyelesaian tugas secara tim (teamwork), pengujian mental dari setiap anggota kelompok, serta menguji kemampuan fisik. Rocmah (2012:10) menjelaskan, "Tujuan outbound adalah menggali dan meningkatkan kemampuan yang dimiliki oleh anak melalui berbagai permainan yang ada yang dibuat menantang melalui media alam".

Secara terperinci Sugandi (2013:8) menjelaskan tentang tujuan dari kegiatan outbound sebagai berikut :

1. Meningkatkan kemampuan mengenal diri dan orang lain.

2. Melatih ketahanan mental dan pengendalian diri.

3. Melahirkan semangat kompetisi yang sehat.

4. Meningkatkan jiwa kepemimpinan

5. Meningkatkan kemampuan mengambil keputusan dalam situasi sulit secara cepat dan akurat.

6. Membangun rasa percaya diri.

7. Meningkatkan rasa kebutuhan akan pentingnya kerja tim untuk mencapai sasaran secara optimal.

Manfaat yang ada pada kegiatan outbound ini sangat banyak seperti mengetahui kemampuan diri sendiri, kemampuan teman satu tim, memberikan fresh brain (otak yang segar) kembali ke kampus atau tempat kerja dan siap menerima materi perkuliahan atau pekerjaan, menumbuhkan mental yang kuat dalam menghadapi tekanan-tekanan pekerjaan atau tugas perkuliahan, dan banyak lagi. Hal ini sesuai dengan pendapat Sugandi (2013:11) menyebutkan :

1. Terbentuknya suatu tim yang solid dengan kinerja yang efektif yang mengahasilkan outcome yang maksimal dalam pencapaian tujuan pendidikan.

2. Terbentuknya kerja sama antar-pribadi, antar-fungsi dan antar-lapisan dalam pendidikan.

3. Meningkatkan para siswa terhadap masalah sesama dalam pendidikan.

4. Menumbuhkan sikap saling empathy yang dalam diantara sesama siswa. 
5. Menjadikan tim kerja dalam belajar lebih siap terhadap perubahan dan perkembangan dunia pendidikan.

Berdasarkan penjelasan tentang tujuan dan manfaat di atas, penulis menyimpulkan bahwa outbound sangat banyak sekali tujuan/sasaran yang diharapkan serta manfaatnya pun sangat banyak sekali dalam membentuk manusia yang siap menerima menjalankan fungsinya sebagai manusia dengan tingkat mobilitas dan kreatifitas yang tinggi dalam menjalankan tugasnya baik pada dunia pekerjaan maupun pada dunia pendidikan terhadap mahasiswa PJKR tingkat 2 yang kewajibannya adalah menuntut ilmu.

Kegiatan outbound yang sudah dilaksanakan oleh prodi Pendidikan Jasmani pada tanggal 25 Januari 2015 terdiri dari tiga program outbound, yaitu :

1. Achievement Motivation Outbound. Artinya Program outbound yang bertujuan untuk meningkatkan motivasi keberhasilan dalam memecahkan suatu tugas yang harus diselesaikan dengan baik.

2. Leadership Outbound Training. Artinya Program outbound yang bertujuan untuk membina dan mengembangkan kepemimpinan di dalam kelompok kerja.

3. Team Building Outbound. Artinya program outbound ini bertujuan untuk membangun kerjasama tim (teamwork) yang serasi dan selaras.

Jenis games yang dilaksanakan adalah dua, yaitu low rope games dan banana games.

Untuk low rope games terdapat enam klasifikasi materi games, yaitu :

1. Catchen Crawl. Bentuk games ini dibentangkan dua kabel sling baja uk. $\varnothing 10 \mathrm{~mm} \times 10$ meter secara horizontal, jarak diantara dua kabel seling baja $\pm 50 \mathrm{~cm}$. Mahasiswa harus melewati rintangan ini dengan merangkak ( $\mathrm{crawl}$ ) Permainan ini diwajibkan setiap mahasiswa harus melewati dua kabel dengan cara merangkak, ke dua kaki menginjak kabel sling baja dibelakang dank ke dua tangan memegang sling baja di depan.

2. Two line bridge. Bentuk games ini dibentangkan dua kabel sling baja uk. $\varnothing 10 \mathrm{~mm} \mathrm{x}$ 10 meter yang satu kabel sling baja sebagai pijakan kaki dan satu lagi sebagai pegangan tangan dengan jarak antara kabel sling baja $\pm 1.60 \mathrm{~m}$. Permainan ini mengharuskan setiap mahasiswa melewati rintangan ini dengan cara berdiri dan berjalan secara menyamping.

3. Elvis travers. Bentuk games ini hampir sama dengan two lines bridge namun jarak antara kabel sling baja atas dan bawah berjarak \pm 3 meter. Pada kabel sling baja bagian atas diberikan tali menggantung panjangnya \pm 3 meter, sedangkan banyaknya tali yang dipasang pada kabel sling baja berjumlah 5 buah tali. Permainan ini mengharuskan mahasiswa untuk melewati dengan berjalan dengan tumpuan kaki melangkah pada kabel sling baja pada bagian bawah dan pegangan tangan harus dapat meraih tali yang di pasang pada kabel sling baja yang ada di atas.

4. Commando crawl. Bentuk games ini dibentangkan satu kabel sling baja uk. $\varnothing 10 \mathrm{~mm} \mathrm{x}$ 10 meter. Permainan ini mengharuskan mahasiswa melewati kabel sling baja tersebut dengan cara merayap seperti yang biasa dilakukan pada pelatihan militer. Yaitu dengan cara tidur telungkup di atas kabel sling baja, ke dua tangan memegang kabel sling baja di depan muka, sedangkan kaki mengaitkan bagian angkle pada kabel sling baja dan satu kaki lagi di luruskan ke bawah sebagai penyeimbang agar stabil posisi tubuhnya.

5. Tarzan travers. Bentuk games ini dibentangkan dua kabel sling baja uk. $\varnothing 10 \mathrm{~mm} \times 10$ meter. Satu kabel sling baja sebagai pijakan kaki untuk berjalan dan satu lagi sling baja di atas kepala dengan jarak $\pm 8 \mathrm{~m}$, dan di tengah kabel sling baja yang ada di atas diikatkan tali dengan panjang 10-12 m. Permainan ini mengharuskan setiap mahasiswa berdiri dan harus berjalan pada kabel sling baja dan ke dua tangan memegang tali yang diikatkan pada kabel sling baja yang ada di atas.

6. Hebee zebee. Bentuk games ini dibentangkan dua kabel sling baja secara horizontal atau sejajar dengan jarak $50 \mathrm{~m}$. Dan di antara kabel tersebut diikatkan tali secara 
diagonal sehingga mirip seperti jembatan yang ada pegangannya. Permainan ini mengaruskan setiap mahasiswa harus dapat melewati jembatan tali dengan cara berjalan secara menyamping dengan pegangan ke dua tangan adalah tali yang diikatkan secara diagonal. Untuk bentuk banana games secara berkelompok yang berjumlah 10 orang mahasiswa (1 orang bertugas sebagai komando, 1 orang kemudi dan 8 orang mahasiswa bertugas mendayung). Permainan ini harus melewati tanda yang ada di air atau danau dengan sempurna tanpa menyentuh tanda atau patok serta harus dapat memindahkan banana boat melewati rintangan jaring secepat mungkin.

\section{KESIMPULAN}

Rutinitas kegiatan outbound yang dilaksanakan secara rutin setiap tahun oleh prodi Pendidikan Jasmani memiliki manfaat yang sangat besar baik secara individu maupun kelompok. Karena di dalam kegiatan tersebut membutuhkan kemampuan diri yang dapat diterapkan dalam kegiatan outbound ini seperti kreativitas, inovatif, ide, dan masih banyak lagi yang dapat dikolaburasikan bersama dengan tim sehingga menciptakan gagasangagasan yang sudah disepakati oleh anggota tim sehingga kerjasma tim (teamwork) dapat dilaksanakan dan dipertanggung jawabkan secara bersama-sama tanpa harus menyalahkan anggota tim.

Kondisi fisik yang harus dibutuhkan dalam kegiatan ini terdiri dari kekuatan, kecepatan, power, daya tahan otot, daya tahan kardiovaskular, fleksibilitas, keseimbangan, koordinasi, kelincahan, akurasi, dan reaksi. Hal ini tergambar dalam pelaksanaan catchen crawl, two line bridge, elvis travers, commando crawl, tarzan travers, dan hebee zebee. $\mathrm{Hal}$ ini berdasarkan hasil wawancara penulis dengan perwakilan dari setiap tim (kelompok peserta) dengan memberikan pertanyaan tentang kondisi fisik yang dibutuhkan dalam kegiatan outbound tersebut.

\section{REKOMENDASI}

Kegiatan outbound yang sudah biasa dilaksanakan secara rutin oleh program studi Pendidikan Jasmani diharapkan dapat dijadikan sebagai cara dalam menumbuhkan kemampuan diri yang dapat diterapkan dalam kegiatan outbound ini seperti kreativitas, inovatif, dan ide dalam menciptakan kerjasama tim dalam setiap kelompoknya serta dapat dijadikan sebagai bahan penelitian bagi peneliti pada bidang outbound.

\section{UCAPAN TERIMA KASIH}

Penulis mengucapkan banyak terima kasih kepada seluruh mahasiswa Pendidikan Jasmani tingkat 2 semester 3 yang terdiri dari mahasiswa reguler dan karyawan yang sudah terlibat dalam kegiatan outbound ini.

\section{DAFTAR PUSTAKA}

Ancok. (2002). Outbound Manajemen Training. Yogyakarta: Uli Press.

Lutan Dkk. (2001). Pendidikan Kebugaran Jasmani. Orientasi Pembinaan Di Sepanjang Hayat. Direktorat Jenderal Olahraga Departemen Pendidikan Nasional. Jakarta.

Subroto. (2010). Didaktik Metodik Pembelajaran Olahraga Permainan. Prodi PJKR. Fakultas Pendidikan Olahraga Dan Kesehatan. UPI. Bandung.

Sugandi. (2013). Konsep Kepemimpinan Guru Dalam Manajemen Kegiatan Outbound. Program Pascasarjana. Universitas Galuh. Ciamis. 
Suherman. (2009). Revitalisasi Pengajaran Dalam Pendidikan Jasmani. CV. Bintang Warli Artika. Bandung.

Sujarwo. (2011). Modul Outbound. Fakultas Ilmu Keolahragaan.Universitas Negeri Yogyakarta. Yogyakarta.

Susapti. (2009). Pembelajaran Berbasis Alam. Sekolah Tinggi Agama Islam Negeri (STAIN) Salatiga.

Rahyubi. (2012). Teori-Teori Belajar dan Aplikasi Pembelajaran Motorik. Penerbit Nusa Media. Bandung.

Balicamp. (2014). Balicamp Training, Outbound, dan Event Organizer. Tabanan. Bali.

Rocmah. (2012). Model Pembelajaran Outbound Untuk Anak Usia Dini. Fakultas Keguruan dan Ilmu Pendidikan Universitas Muhammadiyah. Sidoarjo 